\title{
Relationship between the Yield Strength-Fracture Toughness Balance and the Multiscale Microstructure of a Maraging Stainless Steel for Aircraft Applications
}

\author{
Charline Le Nué ${ }^{*}$, Jean-Marc Cloué ${ }^{2}$, Marie-Hélène Mathon ${ }^{3}$, \\ Sylvain Puech ${ }^{4}$, Denis Béchet ${ }^{4}$ and Denis Delagnes ${ }^{1}$ \\ ${ }^{1}$ Université de Toulouse ; CNRS, Mines Albi, INSA, UPS, ISAE ; ICA (Institut Clement Ader) ; \\ Campus Jarlard, F-81013 Albi, France \\ ${ }^{2}$ Université de Toulouse, Institut Carnot CIRIMAT, INPT-ENSIACET, 4 allée Emile Monso, \\ BP-44362, 31432 Toulouse Cedex 4, France \\ ${ }^{3}$ Laboratoire Léon Brillouin, CEA-CNRS, IRAMIS, 91191 Gif-sur-Yvette, France \\ ${ }^{4}$ Aubert \& Duval, BP-1, 63770 Les Ancizes-Comps Cedex, France
}

\begin{abstract}
Keywords: Maraging steel; Intermetallic precipitation; Yield Strength.
\end{abstract}
\begin{abstract}
Two grades of Fe-Cr-Ni-Al-Ti-Mo maraging steels, with a different titanium content, were investigated. Particular attention was given to the correlation between the precipitated phases and the yield strength. Synchrotron X-ray diffraction, small-angle neutron scattering and atom probe experiments were performed to determine the crystal structure, shape, size distribution, chemical composition, particle number density and volume fraction of precipitates. Both alloys show a strong increase in strength after an aging treatment, which is attributed to the coprecipitation of two different intermetallic phases. Strengthening by a single precipitation of $\beta$ $\mathrm{Ni}(\mathrm{Al}, \mathrm{Ti})$ particles induces a saturation of yield strength around $1600 \mathrm{MPa}$ above a volume fraction of $6 \%$. The improvement of yield strength is then obtained by introducing a nanoscale coprecipitation of $\eta-\mathrm{Ni}_{3}(\mathrm{Ti}, \mathrm{Al})$ phase.
\end{abstract}

\section{Introduction.}

Stainless maraging steels are based on a Fe-Cr-Ni system with some substitutional elements, such as $\mathrm{Mo}, \mathrm{Co}, \mathrm{Cu}, \mathrm{Al}$ and Ti. The good combination of high strength and toughness is obtained by the formation of a high density of homogeneously distributed intermetallic precipitates in a Ni-rich martensitic matrix. Different types of precipitates may form during aging, depending upon composition and heat treatment conditions.

The precipitation behavior and strengthening mechanisms in cobalt-free maraging steels have been extensively studied in the past, by means of various characterization techniques, such as transmission electronic microscopy (TEM), atom probe and X-ray diffraction analysis. It has been shown that Al-containing maraging steels are strengthened by the ordered $\beta$-NiAl phase [1-3]. The particles show a spherical shape and they are homogeneously distributed within the matrix [4]. In contrast, the strengthening of Ti-containing maraging steels is due to the formation of hexagonal $\eta$ $\mathrm{Ni}_{3} \mathrm{Ti}$ phase [5-7], with a nearly rod-like shape.

Only few studies have been performed in maraging steels, which could be strengthened both by $\mathrm{NiAl}$ and $\mathrm{Ni}_{3} \mathrm{Ti}$ precipitates [8]. Gemperle et al. [9] reported the formation of so-called G-phase $\left(\mathrm{Ti}_{16} \mathrm{Si}_{7} \mathrm{Ni}_{16}\right)$ and $\eta-\mathrm{Ni}_{3} \mathrm{Ti}$ phases for a Fe-Cr-Ni-Al-Ti maraging steels containing silicon $(\approx 1.1 \%$ at $)$ during aging at $525^{\circ} \mathrm{C}$. Leitner et al. [8], who have studied the precipitation in Si-free Fe-Cr-Ni-AlTi maraging steel during aging at $525{ }^{\circ} \mathrm{C}$ for $3 \mathrm{~h}$ and $10 \mathrm{~h}$, by means of atom probe tomography (APT) and TEM, show that the precipitation strengthening can therefore be associated with both the $\eta-\mathrm{Ni}_{3} \mathrm{Ti}$ and the $\beta$-NiAl phases.

However, the literature clearly reveals that more work is needed to understand the effect of the different microstructural constituents on the mechanical properties of maraging steels, especially in Fe-Cr-Ni-Mo-Al-Ti maraging steels. Thus, this study focuses on the effect of the co-precipitation of $\beta-\mathrm{Ni}(\mathrm{Al}, \mathrm{Ti})$ and $\eta-\mathrm{Ni}_{3}(\mathrm{Ti}, \mathrm{Al})$ phases on yield strength (Ys), to reach the requested $\mathrm{Ys}(>1700 \mathrm{MPa})$. 


\section{Experimental.}

Two grades of maraging stainless steel (MLX17 and MLX19), developed by the Aubert\&Duval Company, were selected. Their compositions are listed in Table 1. All specimens were solution annealed at $850^{\circ} \mathrm{C}$ for $2 \mathrm{~h}$, followed by a quench to room temperature and a cryogenic treatment at $80^{\circ} \mathrm{C}$ for $8 \mathrm{~h}$. Reference aging was performed at $510^{\circ} \mathrm{C}$ for $8 \mathrm{~h}$, followed by water quenching. Different mechanical properties could be obtained with different aging conditions: $530^{\circ} \mathrm{C} / 1 \mathrm{~h}$.

Table 1. Chemical composition of the maraging steels investigated (in at.\%).

\begin{tabular}{ccccccc}
\hline & Fe & Cr & Ni & Mo & Al & Ti \\
\hline MLX17 & Bal. & 12.7 & 10,3 & 1,2 & 3,1 & 0,3 \\
MLX19 & Bal. & 10.6 & 11,5 & 1,2 & 3,0 & 1,3 \\
\hline
\end{tabular}

Conventional tensile and fracture toughness tests were performed to study the effect of the nanoscale precipitation on mechanical properties. Synchrotron X-ray diffraction (XRD), smallangle neutron scattering (SANS) and three-dimensional atom probe (3-DAP) experiments were performed to analyze the crystal structure, size, volume fraction and chemical composition of precipitates.

XRD measurements were performed at the European synchrotron radiation facility (ESRF, Grenoble, France). The photon energy used for the measurements was $87 \mathrm{keV}$, corresponding to a wavelength of $0.1424 \AA$.

The neutron scattering experiments were performed on PAXY small-angle spectrometer of the ORPHEE facility, at the Léon Brillouin Laboratory (LLB, Saclay, France). The samples were magnetized to saturation in a field of $1.7 \mathrm{~T}$, which was applied perpendicularly to the neutron incident beam. Two different setups were used for the SANS experiments: the sample-detector distances were 5 and $2 \mathrm{~m}$, with a selected wavelength of 9 and $6 \AA$, respectively. Measured intensities were corrected for the sample transmission, background intensity and detector response using standard computer programs of the Léon Brillouin Laboratory [10]. The analysis method has been reported elsewhere [11,12]. These experiments give access to the mean size of small particles $(<10 \mathrm{~nm})$, as well as the full width at the half maximum of the gaussian distributions. The particle number densities $N_{p}$ were estimated, following the methods given in references [13,14].

The three-dimensional atom probe analyses were carried out on a LEAP 4000 HR from Cameca Instruments, in the laboratory of the Groupe de Physique des Matériaux (GPM, Rouen, France). Samples were performed by means of blanks of $0.3 \times 0.3 \times 15 \mathrm{~mm}^{3}$, that were converted into needles by electropolishing in 5\% perchloric acid (70\%) in acetic acid $(90 \%)$ at $15 \mathrm{~V}$ at room temperature.

\section{Results.}

\section{Mechanical tests.}

The measured characteristics extracted from the mechanical tests are given in Table 2. In the solution annealed state, both alloys show a relatively low strength and high ductility. The aged state results in a significant increase in strength and a decrease of the ductility, as compared to the annealed state. After the aging treatment, MLX19 has a higher level of resistance than MLX17 (a difference of nearly $130 \mathrm{MPa}$ for the yield strength and $180 \mathrm{MPa}$ for the ultimate tensile strength), but a lower value of fracture toughness.

Table 2. Tensile properties of the investigated steels ( $\mathrm{SA}=$ solution annealed, $\mathrm{A}=$ after aging).

\begin{tabular}{lccccc}
\hline & State & Ys $(0.2 \%$ off-set $)[\mathrm{MPa}]$ & UTS [MPa] & $e_{\mathrm{f}}[\%]$ & $\mathrm{K}_{\mathrm{IC}}[\mathrm{MPa} \sqrt{\mathrm{m}}]$ \\
\hline MLX17 & SA & 672 & 962 & 17.0 & - \\
& SA + A & 1648 & 1732 & 12.1 & 79 \\
MLX19 & SA & 708 & 1040 & 17.5 & - \\
& SA + A & 1782 & 1912 & 9.9 & 53 \\
\hline
\end{tabular}

Ys=yield strength, UTS=ultimate tensile strength, $e_{\mathrm{f}}=$ elongation at fracture, $\mathrm{K}_{\mathrm{IC}}=$ plane strain fracture toughness. 


\section{Microstructural investigation.}

Synchrotron X-ray diffraction experiments were carried out to identify the crystal structure of the nanoscale precipitation and to estimate the volume fraction of retained austenite. Fig. 1 shows the XRD patterns of the steels, after the austenitizing treatment (in grey) and after the aging treatment of $8 \mathrm{~h}$ at $510^{\circ} \mathrm{C}$ (in black), for MLX17 and MLX19 respectively. In the solution annealed state, the steels contain a low amount of retained austenite (volume fraction of $2 \%$ and $4 \%$ for steels MLX17 and MLX19 respectively). For MLX17, the aging results in the formation of ordered $\beta$-NiAl phase (structure B2). The $\eta-\mathrm{Ni}_{3} \mathrm{Ti}$ phase is not identified by XRD. For MLX19, XRD results show the formation of two intermetallic phases, identified as ordered $\beta$-NiAl phase and $\eta-\mathrm{Ni}_{3} \mathrm{Ti}$ phase (structure $\mathrm{D}_{24}$ ). The amount of austenite does not significantly evolve after aging (volume fractions of 2\% and 5\% for MLX17 and MLX19 respectively).
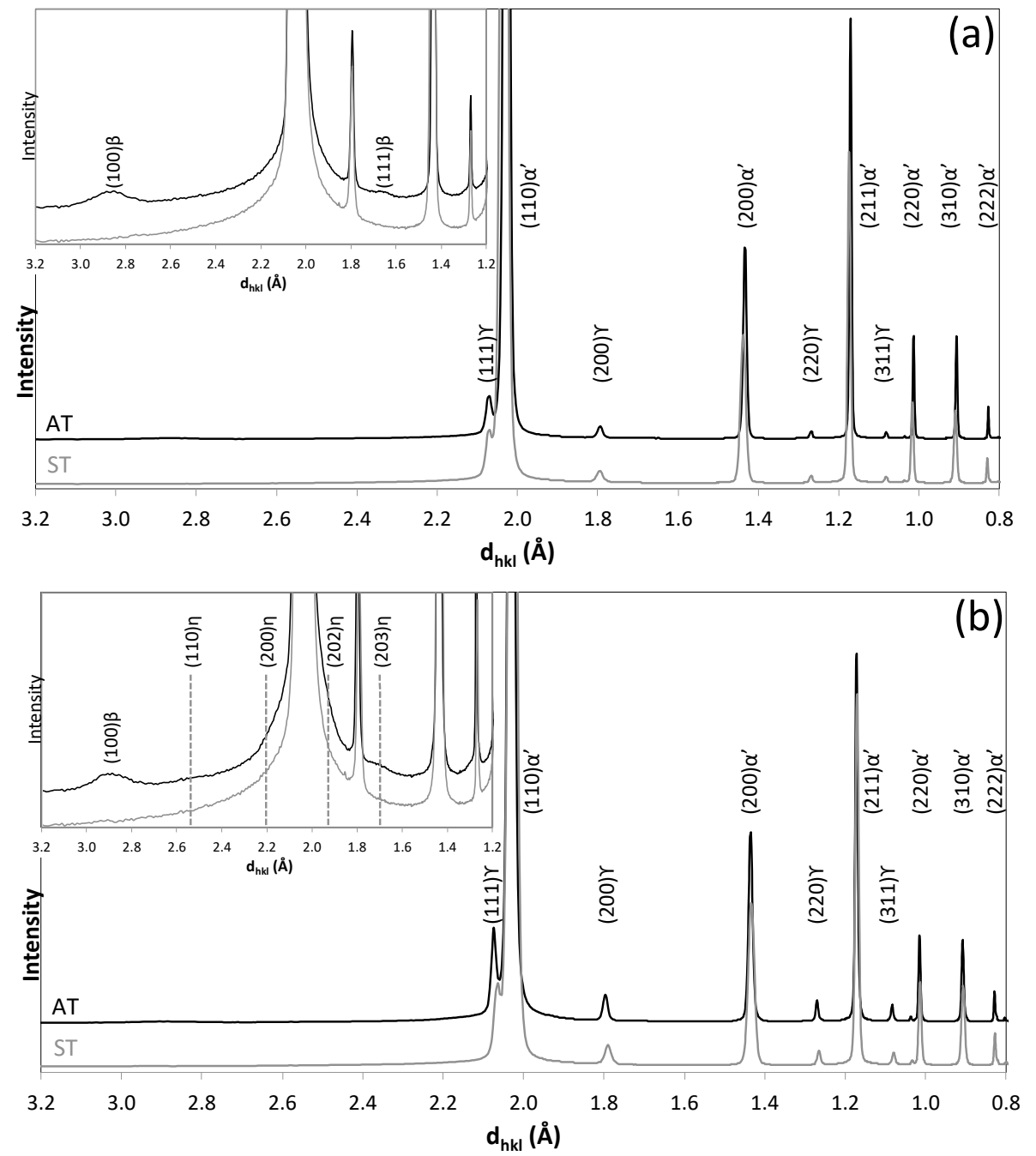

Fig. 1. X-ray diffraction patterns of the steels after the solution treatment (ST) and after the aging treatment (AT). (a) MLX17; (b) MLX19.

The mean size, the full width at the half maximum (FWHM) of the gaussian distributions and the particle number density $N_{p}$ were obtained from the SANS experiments (Table 3 ).

Table 3. Data obtained from SANS experiments (data treatments are described in ref. [10-13]).

\begin{tabular}{ccccc}
\hline & Aging Treatment & $<\mathrm{R}>[\mathrm{nm}]$ & FWHM $[\mathrm{nm}]$ & $N_{p}\left[10^{24} \mathrm{~m}^{-3}\right]$ \\
\hline MLX17 & $530^{\circ} \mathrm{C} / 1 \mathrm{~h}$ & 2.0 & 0.45 & 2.1 \\
MLX17 & $510^{\circ} \mathrm{C} / 8 \mathrm{~h}$ & 2.2 & 0.70 & 1.7 \\
MLX19 & $510^{\circ} \mathrm{C} / 8 \mathrm{~h}$ & 2.6 & 0.80 & 1.4 \\
\hline
\end{tabular}

After $8 \mathrm{~h}$ of aging, two types of Ni-Ti-Al rich particles are clearly identified using APT analysis, as shown in Fig. 2. The first population contains only spherical shape particles. The composition in 
the core of $\mathrm{Ni}-\mathrm{Ti}-\mathrm{Al}-\mathrm{rich}$ particles was measured to be $54 \mathrm{Ni}-2.5 \mathrm{Ti}-29 \mathrm{Al}-13 \mathrm{Fe}-1.5 \mathrm{Cr}$ (at $\%$ ) for MLX17, and 53Ni-11Ti-23Al-11Fe-2Cr (at\%) for MLX19. Considering previous results obtained in similar steels [8], this first population can be associated with the $\beta$-Ni(Al,Ti) precipitation. Conversely, the second population shows an elongated shape. The composition in the core of Ni-TiAl-rich particles was determined to be $66 \mathrm{Ni}-14 \mathrm{Ti}-12 \mathrm{Al}-5 \mathrm{Fe}-2 \mathrm{Cr}$ (at $\%$ ) for MLX17, and 71Ni-18Ti$8 \mathrm{Al}-1 \mathrm{Fe}-2 \mathrm{Cr}(\mathrm{at} \%)$ for MLX19, which is consistent to associate those particles to the $\eta-\mathrm{Ni}_{3}(\mathrm{Ti}, \mathrm{Al})$ phase. The chemical composition of the matrix was measured by atom probe analysis (Table 4). From this information and the chemical compositions of intermetallic phases, the volume fractions of particles were estimated (Table 5).

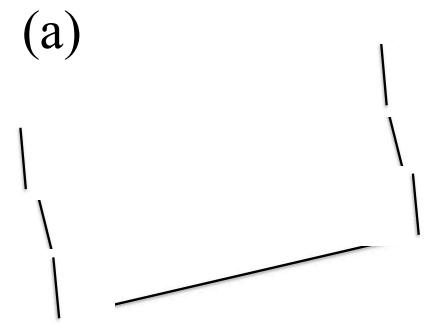

(b)

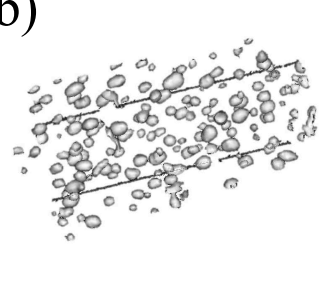

Fig. 2. Atom probe analysis after $8 \mathrm{~h}$ of aging at $510{ }^{\circ} \mathrm{C}$. Isoconcentration surface for regions containing $>15 \% \mathrm{Al}$ (light gray surface) and $>4 \% \mathrm{Ti}$ (dark gray surface). (a) MLX17 (box size $110 \mathrm{x}$ $40 \times 40 \mathrm{~nm}^{3}$ ); (b) MLX19 (box size $100 \times 40 \times 40 \mathrm{~nm}^{3}$ ).

Table 4. Chemical composition of the matrix obtained by APT analysis. (in at.\%).

\begin{tabular}{ccccccc}
\hline & Fe & Cr & Ni & Mo & Al & Ti \\
\hline MLX17 & Bal. & 12.24 & 7.06 & 1.27 & 1.35 & 0.10 \\
MLX19 & Bal. & 8.92 & 6.69 & 1.20 & 1.12 & 0.24 \\
\hline
\end{tabular}

\section{Discussion.}

The measured yield strength and volume fraction of particles are compared with data from the literature (Table 5) obtained in maraging steels.

Table 5. Atom probe results of the precipitate analysis and tensile properties of the maraging steels (*Ni(Al,Ti);** $\left.\mathrm{Ni}_{3}(\mathrm{Ti}, \mathrm{Al})\right)$. Symbols are attributed to the corresponding grades in next plots.

\begin{tabular}{|c|c|c|c|c|}
\hline & Symbol & Aging & Phase fraction [vol.\%] & Yield strength [MPa] \\
\hline \multirow{2}{*}{ MLX17 } & $\diamond$ & $530^{\circ} \mathrm{C} / 1 \mathrm{~h}$ & $5.86 * / 0.94 * *$ & 1620 \\
\hline & 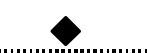 & $510^{\circ} \mathrm{C} / 8 \mathrm{~h}$ & $7.69 * / 0.97 * *$ & 1648 \\
\hline MLX19 & O & $510^{\circ} \mathrm{C} / 8 \mathrm{~h}$ & $8.10 * / 3.85 * *$ & 1782 \\
\hline $13 \mathrm{Cr}-8 \mathrm{Ni}-2.5 \mathrm{Mo}-2 \mathrm{Al}[4]$ & 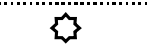 & $450^{\circ} \mathrm{C} / 4 \mathrm{~h}$ & $1^{*}$ & 1240 \\
\hline \multirow{2}{*}{ PH13-8Mo $[15,16]$} & $\triangle$ & $525^{\circ} \mathrm{C} / 3 \mathrm{~h}$ & $8.4^{*}$ & 1609 \\
\hline & $\Delta$ & $525^{\circ} \mathrm{C} / 10 \mathrm{~h}$ & $11.1 *$ & 1593 \\
\hline \multirow{2}{*}{ PH13-8Mo [17,18] } & $\square$ & $575^{\circ} \mathrm{C} / 5 \mathrm{~h}$ & $3.2 *$ & 1299 \\
\hline & & $575^{\circ} \mathrm{C} / 10 \mathrm{~h}$ & $3.5^{*}$ & 1246 \\
\hline
\end{tabular}

Using Table 5 , the yield strength according to the volume fraction of $\beta$-Ni(Al,Ti) particles determined by APT is shown in Fig. 3. For volume fraction values lower than $6 \%$, a large increase in the yield strength from $1240 \mathrm{MPa}$ to nearly $1600 \mathrm{MPa}$ is observed (Fig. 3). The increase of the yield strength seems to be strongly related to the volume fraction of $\beta$-Ni(Al,Ti) particles. Above $6 \%$, a saturation of the yield strength is found, especially for MLX17 and therefore, increasing the phase fraction of $\beta$-Ni(Al,Ti) above a critical value becomes inefficient. However, both steels MLX17 and MLX19 present a higher level of yield strength (>1600 MPa) than Ti-free maraging steels which is probably due to the co-precipitation of the $\eta-\mathrm{Ni}_{3}(\mathrm{Ti}, \mathrm{Al})$ particles as shown in Fig. 4.

After an aging of $8 \mathrm{~h}$ at $510^{\circ} \mathrm{C}$, the particle number density of $\beta$-Ni(Al,Ti), estimated from SANS experiments, is extremely high $\left(1.7 \times 10^{24} \mathrm{~m}^{-3}\right.$ for MLX17 and $1.4 \times 10^{24} \mathrm{~m}^{-3}$ for MLX19). Increasing the particle density would cause a decrease of the distance between particles and, as described by $\mathrm{P}$. 
Michaud et al. [13], the strengthening effect is saturated when dislocations inherited from the quench interacts with a large amount of precipitates as previously described into the literature. Hence, for a further improvement of the yield strength, it is necessary to form new type of efficient obstacles inducing different local stress at the interface with the matrix. The increase of yield strength $\Delta Y$ s according to the volume fraction of $\eta-\mathrm{Ni}_{3}(\mathrm{Ti}, \mathrm{Al})$ phase is presented in Fig. 4 . The increase of yield strength $\Delta Y s$ is calculated as the difference between the measured $Y s$ and the maximum saturated Ys for a single precipitation of $\beta$-Ni(Al,Ti) particles (1600 MPa). As shown in Fig. 4, an improvement in yield strength is obtained by introducing a nanoscale precipitation of $\eta$ $\mathrm{Ni3}(\mathrm{Ti}, \mathrm{Al})$. The beneficial effect of a co-precipitation in increasing the mechanical resistance has already been demonstrated in in other steels, for instance by combining carbides and intermetallic precipitation $[19,20]$. However, this beneficial effect due to $\eta-\mathrm{Ni} 3(\mathrm{Ti}, \mathrm{Al})$ precipitation induces a strong decrease of the fracture toughness (Table 2 : nearly 80 to $50 \mathrm{MPa} \sqrt{\mathrm{m}}$ ) for MLX19.

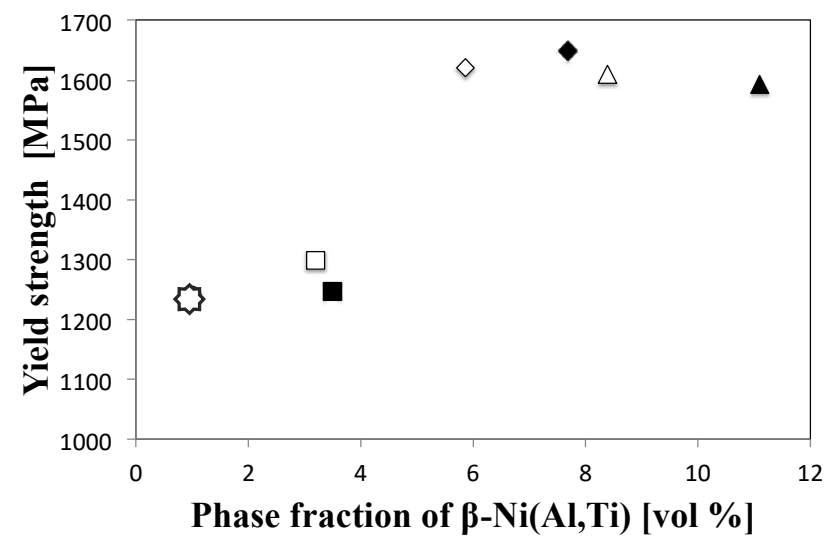

Fig. 3. Experimental yield strength according to the volume fraction of $\mathrm{Ni}(\mathrm{Al}, \mathrm{Ti})$ phase.

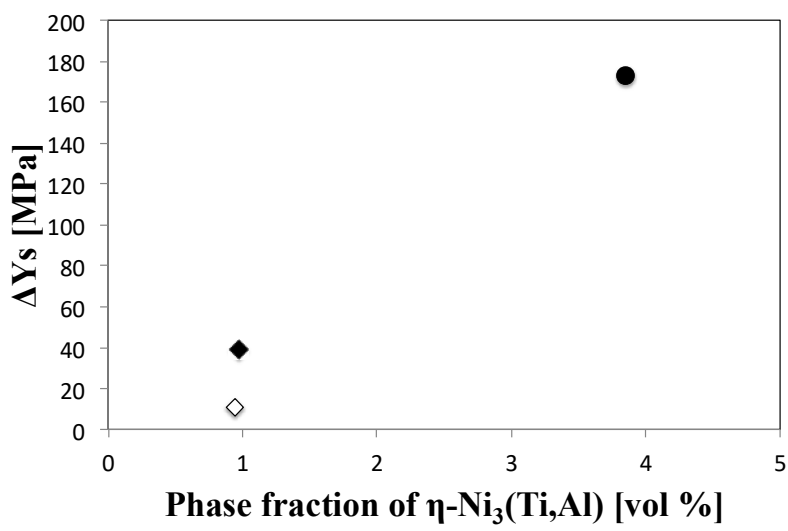

Fig. 4. Increase of yield strength according to the volume fraction of $\eta-\mathrm{Ni}_{3}(\mathrm{Ti}, \mathrm{Al})$.

\section{Summary}

In conclusion, this study shows a significant improvement in yield strength by introducing a nanoscale co-precipitation in Fe-Ni-Al maraging steels. However, this beneficial effect due to coprecipitation induces a strong decrease of the fracture toughness. To reach the requested yield strength $(>1700 \mathrm{MPa})$, while keeping the initial value of the fracture toughness, it is necessary to better understand the mechanisms controlling the decrease of the fracture toughness at high strength. This is a real challenge. In this way, the effect of the cooling conditions, after each step of heat treatment, is currently being studied.

\section{Acknowledgements}

Special thanks are given to Dr. F. Danoix from GPM-CNRS for invaluable help in the realization and analysis of atom probe experiments.

\section{References}

[1] V. Seetharaman, M. Sundararaman, R. Krishnan, Precipitation Hardening in a PH 13-8 Mo Stainless Steel, Mater. Sci. Eng. 47 (1981) 1-11.

[2] Z. Guo, W. Sha, D. Vaumousse, Microstructural evolution in a PH13-8 stainless steel after ageing, Acta Mater. 51 (2003) 101-116.

[3] R. Taillard, A. Pineau, B.J. Thomas, The Precipitation of the Intermetallic Compound NiAI in Fe-19wt.\%Cr Alloys, Mater. Sci. Eng. 54 (1982) 209-219. 
[4] D.H. Ping, M. Ohnuma, Y. Hirakawa, Y. Kadoya, K. Hono, Microstructural evolution in $13 \mathrm{Cr}-8 \mathrm{Ni}-2.5 \mathrm{Mo}-2 \mathrm{Al}$ martensitic precipitation-hardened stainless steel, Mater. Sci. Eng. A. 394 (2005) 285-295.

[5] W. Sha, A. Cerezo, G.D.W. Smith, Phase Chimistry and Precipitation Reactions in Maraging Steels: Part II. Co-Free T-300 Steel, Metall. Trans. A. 24 (1993) 1233-1239.

[6] V.M. Kardonskii, M.D. Perkas, Aging of Martensite in Fe- Ni- Mn steels, Metalloved. I Termicheskaya Obrab. Met. (1966) 7-10.

[7] V.K. Vasudevan, S.J. Kim, C.M. Wayman, Precipitation Reactions and Strengthening Behavior in 18 Wt Pct Nickel Maraging Steels, Metall. Trans. A. 21 (1990) 2655-2668.

[8] H. Leitner, M. Schober, R. Schnitzer, Splitting phenomenon in the precipitation evolution in an Fe-Ni-Al-Ti-Cr stainless steel, Acta Mater. 58 (2010) 1261-1269.

[9] A. Gemperle, J. Gemperlova, W. Sha, G.D.W. Smith, Aging behaviour of Cobalt free chromium containing maraging steels, Mater. Sci. Technol. 8 (1992) 546-554.

[10] M.H. Mathon, C.H. de Novion, De l'intensité à la structure des matériaux, J. Phys. IV. 9 (1999) 127-146.

[11] D. Delagnes, P. Lamesle, M.H. Mathon, N. Mebarki, C. Levaillant, Influence of silicon content on the precipitation of secondary carbides and fatigue properties of a $5 \% \mathrm{Cr}$ tempered martensitic steel, Mater. Sci. Eng. A. 394 (2005) 435-444.

[12] M.H. Mathon, A. Barbu, F. Dunstetter, F. Maury, N. Lorenzelli, C.H. de Novion, Experimental study and modelling of copper precipitation under electron irradiation in dilute $\mathrm{FeCu}$ binary alloys, J. Nucl. Mater. 245 (1997) 224-237.

[13] P. Michaud, D. Delagnes, P. Lamesle, M.H. Mathon, C. Levaillant, The effect of the addition of alloying elements on carbide precipitation and mechanical properties in $5 \%$ chromium martensitic steels, Acta Mater. 55 (2007) 4877-4889.

[14] M. Perrut, M.-H. Mathon, D. Delagnes, Small-angle neutron scattering of multiphase secondary hardening steels, J. Mater. Sci. 47 (2012) 1920-1929.

[15] H. Leitner, M. Schober, R. Schnitzer, S. Zinner, Strengthening behavior of Fe-Cr-Ni-Al(Ti) maraging steels, Mater. Sci. Eng. A. 528 (2011) 5264-5270.

[16] M. Schober, R. Schnitzer, H. Leitner, Precipitation evolution in a Ti-free and Ti-containing stainless maraging steel., Ultramicroscopy. 109 (2009) 553-562.

[17] R. Schnitzer, S. Zinner, H. Leitner, Modeling of the yield strength of a stainless maraging steel, Scr. Mater. 62 (2010) 286-289.

[18] R. Schnitzer, R. Radis, M. Nöhrer, M. Schober, R. Hochfellner, S. Zinner, et al., Reverted austenite in PH 13-8 Mo maraging steels, Mater. Chem. Phys. 122 (2010) 138-145.

[19] W.M. Garrison, R. Strychor, A Preliminary Study of the Influence of Separate and Combined Aluminum and Nickel Additions on the Properties of a Secondary Hardening Steel, Metall. Trans. A. 19 (1988) 3103-3107.

[20] S.D. Erlach, H. Leitner, M. Bischof, H. Clemens, F. Danoix, D. Lemarchand, et al., Comparison of NiAl precipitation in a medium carbon secondary hardening steel and C-free PH138 maraging steel, Mater. Sci. Eng. A. 429 (2006) 96-106. 